\title{
Lidar/radar approach to quantify the dust impact on ice nucleation in mid and high level clouds
}

\author{
Albert Ansmann ${ }^{1, *}$, Rodanthi-Elisavet Mamouri ${ }^{2}$, Johannes Bühl ${ }^{1}$, Patric Seifert ${ }^{1}$, Ronny Engelmann ${ }^{1}$, Agyro Nisantzi $^{2}$, \\ Julian Hofer ${ }^{1}$, and Holger Baars ${ }^{1}$ \\ ${ }^{1}$ Leibniz Institute for Tropospheric Research, Leipzig, Germany \\ ${ }^{2}$ Cyprus University of Technology, Limassol, Cyprus
}

\begin{abstract}
We present the first attempt of a closure experiment regarding the relationship between ice nucleating particle concentration (INPC) and ice crystal number concentration (ICNC), solely based on active remote sensing. The approach combines aerosol and cloud observations with polarization lidar, Doppler lidar, and cloud radar. Several field campaigns were conducted on the island of Cyprus in the Eastern Mediterranean from 2015-2018 to study heterogeneous ice formation in altocumulus and cirrus layers embedded in Saharan dust. A case study observed on 10 April 2017 is discussed in this contribution.
\end{abstract}

\section{Introduction}

Heterogeneous ice formation is an important pathway of aerosol-cloud interaction. Via heterogeneous nucleation of ice cyrstals, aerosol particles can trigger cloud ice formation at temperatures $>-38^{\circ} \mathrm{C}$ at which homogeneous freezing is impossible. Even at lower temperatures $(-40$ to $-65^{\circ} \mathrm{C}$ ) and dominating homogeneous freezing conditions, heterogeneous ice nucleation can have a strong impact on the evolution and life time of cirrus clouds when the clouds form in dust layers which frequently reach the upper troposphere by long-range transport and large-scale lifting. Because the ice phase is an important prerequisite for the initiation of precipitation (almost everywhere around the globe), mineral dust can sensitively influence the tropospheric water cycle.

Heterogeneous ice nucleation is however not well understood due to the complexity of ice-nucleating efficiencies of atmospheric aerosol mixtures and their specific chemical and microphysical properties [1] and the complicated influences of aerosol particles and air motion (updrafts, downdrafts, turbulence and entrainment) on the nucleation of ice crystals. As a consequence, poorly parameterized aerosol-cloud interaction in atmospheric models is an important source for large uncertainty in weather and climate predictions.

We simply need new ways, new techniques and method-combining measurement concepts and strategies (besides airborne in situ observations) to study and monitor (continuously and coherently) the complex system of aerosol layers, clouds, and precipitation at given meteorological conditions. Active remote sensing from the ground is favorable to simultaneously observe aerosol and cloud fields with high temporal and vertical resolution and thus

*e-mail: albert@tropos.de the evolution of clouds in their natural clean, dusty, or polluted environment. Closure studies of the relationship between ice-nucleating particle concentration (INPC) and ice crystal number concentration (ICNC) are of key importance in investigations of the role of heterogeneous ice nucelation in the evolution of ice-containing cloud layers.

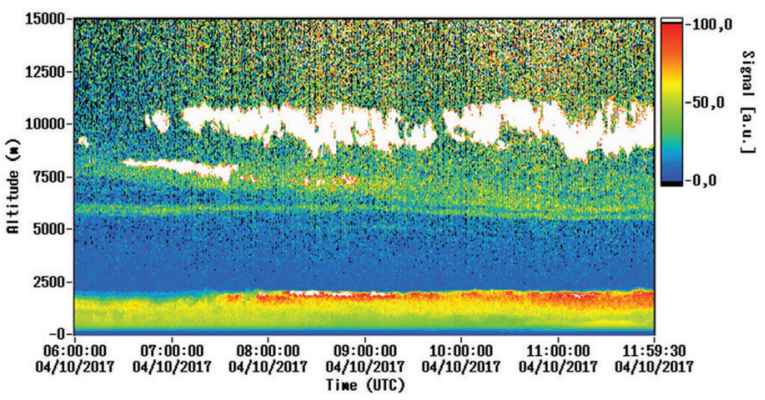

Figure 1. Cirrus layers in the upper troposphere observed on 10 April 2017 over Limassol, Cyprus. The range-corrected $1064 \mathrm{~nm}$ lidar return signal is shown. Between 7.5 and $8.5 \mathrm{~km}$ height a cirrus layer developed in Saharan dust from 6:30 to 7:45 UTC. This case is further analyzed in Fig. 2.

In this contribution we briefly present a new experimental approach to quantify the dust impact on ice formation in the middle and upper troposphere. The technique is solely based on active remote sensing. We show and discuss a case study of an unusually warm cirrus layer which developed at a comparably low altitude of $8.3 \mathrm{~km}$ height. The event occurred on 10 April 2017 over Limassol, Cyprus. The respective cloud temperatures were around $-36^{\circ} \mathrm{C}$. The ice cloud formed in a mineral dust layer which was advected from central and western regions of the Sahara towards the Eastern Mediterranean.

In the framework of a closure experiment, we compare INPC values, estimated from aerosol observations with 


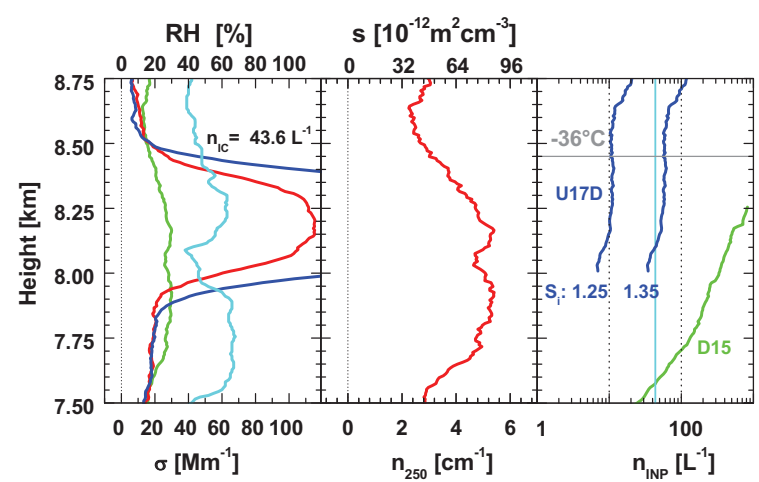

Figure 2. Left panel: Lidar-derived dust extinction coefficient (green) before the formation of the ice cloud, cirrus extinction coefficients (red, blue), and relative humidity (cyan) measured with Limassol radiosonde during the lidar observation on 10 April 2017. The lidar/radar retrieval yielded an ICNC value of $n_{\mathrm{IC}}=43.6 \mathrm{~L}^{-1}$ in the freshly formed ice cloud (given as number in the panel). Center panel: Dust particle number concentration $n_{250}$ (particles with radius $>250 \mathrm{~nm}$, favorable ice nuclei) or particle surface area concentration $s$ derived from the dust extinction coefficient (green lidar profile in the left panel) [2]. Right panel: INPC obtained with different INP parameterization schemes (available in the literature) with $n_{250}$ (D15) [4] and $s$ (U17D) [5] and temperature (from radiosonde or atmospheric model) as input. The green curve shows INPC profiles for immersion freezing and the blue curves show INPC profiles for deposition freezing and ice super saturation values of 1.25 and 1.35. The vertical line indicates the ICNC value of $43.6 \mathrm{~L}^{-1}$ and the dashed curve the uncertainty in the ICNC retrieval. Cloud top temperature is indicated as well.

polarization lidar [2] at cloud top level (before the cloud developed and crossed the lidar site), with the number of produced ice crystals (ICNC) falling out of the cloud layer detected by a combination of wind Doppler lidar and cloud Doppler radar over the remote sensing field site [3]. A successful closure is given when the estimated INPC and ICNC values are in reasonable agreement (within an order of magnitude). In the case of a successful closure we can conclude that heterogeneous ice formations plays a significant role in the evolution of the ice phase of the observed cloud layer.

\section{Field studies}

We tested our remote-sensing approach during several campaigns conducted in Cyprus in each spring of 20152018. Cyprus is located in the Eastern Mediterranean. Middle East climate conditions prevail. As a highlight, we moved the Leipzig Cloudnet stations LACROS (Leipzig Aerosol and $C$ loud Remote $O$ bservations $S$ ystem) to Limassol, Cyprus, for 17 months and run the complex active remote sensing facility consisting of a multiwavelength polarization/Raman lidar, Doppler lidar, cloud
Doppler radar, microwave radiometer, and a disdrometer continuously at the Eastern Mediterranean station in the framework of CyCARE ( $C y$ prus Cloud Aerosol pRecipitaion Experiment) from October 2016 to March 2018. CyCARE was conducted in close cooperation of the Leibniz Institute for Tropospheric Research and the Cyprus University of Technology (CUT), Limassol, Cyprus. All these activities were performed in the framework of the European Research Infrastructure project ACTRIS-2 (Aerosol, Clouds, and Trace gases Research InfraS tructure, https://www.actris.eu/).

Figure 1 provides an overview of the atmospheric conditions on 10 April 2017. An ice cloud developed between 7.5 and $8.5 \mathrm{~km}$ height from 6:30 to 7:45 UTC. The cirrus layer formed in Saharan dust. The planetary boundary layer reached to $2.2 \mathrm{~km}$ height. Dust layers are visible in Fig. 1 at heights above $5.5 \mathrm{~km}$. A thick cirrus layer developed at the tropopause at about $11 \mathrm{~km}$ height and persisted for more than 6 hours.

Figure 2 shows height profiles of the dust and cirrus extinction coefficients at $532 \mathrm{~nm}$ (left panel), dust particle surface area concentration $s$ and particle number concentration $n_{250}$ considering large particles with radius $>250 \mathrm{~nm}$ only (center panel), and INPC profiles obtained by means of different INPC parameterisation schemes (right panel) [2, 4, 5]. From the combined lidar/radar approach the ICNC value of $43.6 \mathrm{~L}^{-1}$ is obtained. This technique analyses the terminal velocity of falling ice crystals to obtain the size distribution of ice crystals and lidar backscatter and radar reflectivity to obtain ICNC [3].

As can be seen in Fig. 2 (right panel), closure is obtained in the case of deposition freezing at an ice supersaturation of about 1.25-1.35. Ice multiplication effects caused by breakup of fragile ice crystals into many pieces would considerably disturb our closure studies. However, these effects of secondary ice production can be ignored in the case of thin stratiform clouds and are usually widely surpressed at temperatures far below $-10^{\circ} \mathrm{C}$ [6]. Thus the observed successful closure suggests that dust triggered the evolution of the observed ice cloud layer.

\section{References}

[1] Hoose, C. and Möhler, O., Atmos. Chem. Phys. 12, 9817-9854 (2012)

[2] Mamouri, R.-E. and Ansmann, A., Atmos. Chem. Phys. 16, 5905-5931 (2016)

[3] Bühl, J. et al., ACP, submitted (2019)

[4] DeMott, P. J. et al., Atmos. Chem. Phys. 15, 393-409 (2015)

[5] Ullrich, R. et al., J. Atmos. Sci. 74, 699-717 (2017)

[6] Sullivan, S. C. et al., Atmos. Chem. Phys. 18, 15931610 (2018) 